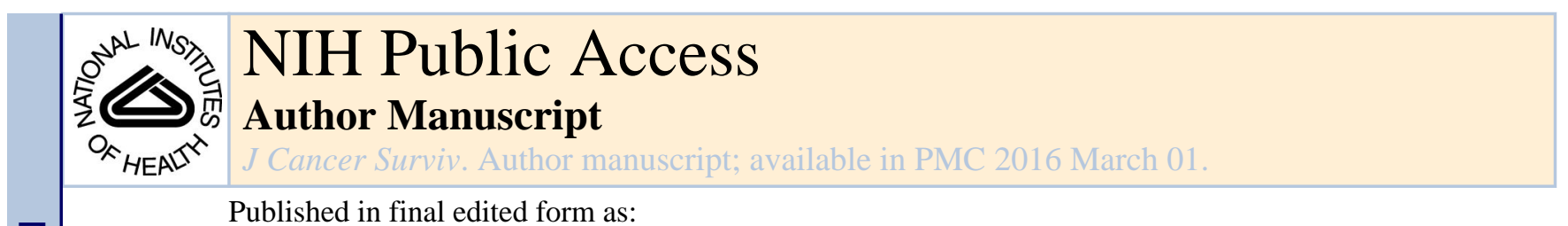

Published in final edited form as:

J Cancer Surviv. 2015 March ; 9(1): 20-29. doi:10.1007/s11764-014-0380-4.

\title{
Career readiness in adult survivors of childhood cancer: a report from the St. Jude Lifetime Cohort study
}

\author{
David Strauser, $\mathrm{PhD}^{1}$, James L. Klosky, $\mathrm{PhD}^{2}$, Tara M. Brinkman, $\mathrm{PhD}^{2}$, Alex W.K. Wong, \\ PhD $^{3}$, Fong Chan, Ph.D. ${ }^{4}$, Jennifer Q. Lanctot, Ph.D. ${ }^{2}$, Rohit P. Ojha, Ph.D. ${ }^{2}$, Leslie L. \\ Robison, Ph.D. ${ }^{2}$, Melissa M. Hudson, Ph. D. ${ }^{2}$, and Kirsten K. Ness, Ph.D. ${ }^{2}$ \\ ${ }^{1}$ University of Illinois Urbana-Champaign, Champaign, IL, USA; strauser@illinois.edu \\ ${ }^{2}$ St. Jude Children's Research Hospital, Memphis, TN. USA \\ ${ }^{3}$ Washington University School of Medicien, St. Louis, MO, USA \\ ${ }^{4}$ University of Wisconsin-Madison, Madison, WI, USA
}

\begin{abstract}
Purpose-Adult survivors of childhood cancer experience difficulties in obtaining and maintaining employment. Employment-related challenges are associated with treatment-related health conditions, and may also be related to vocational factors such as career readiness, skill acquisition, and work experience. Unfortunately, little is known about how treatment, health and vocational related factors interact to impact career development among childhood cancer survivors.

Methods-385 adult survivors of childhood cancer (42.1\% male, median age 38 (21-62) years), participating in the St. Jude Lifetime Cohort study, completed a work experiences survey that included measures of career readiness and vocational identity. Logistic regression was used to compare characteristics of survivors in the low career readiness category to those in the medium or high career readiness category, and structural equation modeling (SEM) was utilized to evaluate associations between career readiness, vocational identity, treatment intensity and physical/ emotional health.
\end{abstract}

Results-Low career readiness was prevalent in $17.4 \%$ of survivors. Univariate analysis did not identify any significant associations between cancer treatment-related factors and career readiness. Unemployed survivors (Odds ratio (OR) 2.3, 95\% Confidence Interval (CI) 1.2-4.5), those who were not college graduates (OR 3.0, 95\% CI 1.6-5.6), and those who had no personal income (OR $5.9,95 \%$ CI 1.7-30.9) were at increased risk of low career readiness. SEM indicated that associations between treatment intensity, physical health, age at diagnosis and career readiness were mediated by emotional health and vocational identity. $63 \%, 35 \%$, and $10 \%$ of the variance in career readiness, vocational identity, and emotional health, respectively, were explained by this theoretical model.

Conflict of Interest

All of the authors declare no conflict of interest. 
Conclusions-The results of this study indicate that individuals who reported low levels of career readiness were more likely to be unemployed, earn less than $\$ 40,000$ per year, and were less likely to graduate from high school. The final structural model indicates that vocational identity and emotional health accounted for the indirect effect of treatment intensity, age a diagnosis, and physical health on career readiness.

Implications for Cancer Survivors-Addressing career readiness may be important to improve employment outcomes for adult survivors of childhood cancer.

\section{Keywords}

Career Readiness; Vocational Identity; Employment; Childhood Cancer Survivor

\section{Introduction}

Young adults surviving childhood cancer experience problems obtaining and maintaining employment [1-5]. A recent meta-analysis reported that childhood cancer survivors are twice as likely as healthy controls to be unemployed; although reasons for unemployment remain unclear [6]. Early attributions for employment-related difficulties include health complications related to cancer treatment, like fatigue or cardiovascular disease [7, 8] but more recently, factors related to career readiness, like work skill acquisition and work experience have been implicated [9]. Treatment-related late symptom burden among survivors may interfere with sensory perception, attention, executive function, physical movement and social skills, which may impact abilities to meet employer demands, and limit work opportunities during adolescence. Developmentally, adolescence is when teens gain skill and experience through school and community organizations, and enter the work force [10-12]. Because of cancer related impairments, adolescent survivors of childhood cancer may be sheltered from typical activities, or have activities selected for them by caregivers, limiting exposure to social and employment experiences that require problem solving, decision making and behavioral adaptation in formal settings [9]. Despite difficulties related to employment after cancer, continued pursuit of one's career is important for adults treated for cancer [13]. Unfortunately, little is known about the factors that impact career development among childhood cancer survivors, who perhaps represent a more vulnerable population.

A Cognitive Information Processing (CIP) framework, typically used in vocational counseling [14-16], may help explain problems experienced by childhood cancer survivors as they seek and maintain employment. This framework is built on the constructs of information, career problem solving and decision-making. Individuals who lack information or have low levels of readiness experience employment difficulties related to job acquisition and maintenance, and may display affective and behavioral states that contribute to negative employment outcomes [17]. In this model, career readiness is comprised of two factors, capability and complexity. Capability refers to the individual's intellectual and emotional ability to make rational decisions, and can be affected by emotional state and intelligence. Complexity refers to the events or circumstances happening in a person's life during the time he or she needs to make a career decision. Poverty, divorce, loss or change of work, and poor health are examples of issues that increase the complexity of the decision the person 
has to make. Theoretically, CIP differs from other related vocational theories in that the primary focus of CIP is on the processing and application of career and vocational information to establish and maintain individual/environment congruence. [15]. Appropriate levels of career readiness provide the foundation for effective work behavior and higher levels of work engagement. Career readiness is also tied to vocational identity, or the ability to gain and maintain a clear and stable structure of meanings in which motivation, interests and competencies are conceptualized and linked to acceptable career and personal roles [15].

Using this CIP model, this manuscript has the following aims: 1) to describe career readiness in terms of demographic variables and treatment history; and 2) to assess the direct and indirect effects of treatment intensity, physical and emotional health, and vocational identity on career readiness in a cohort of childhood cancer survivors.

\section{Methods}

\section{Participants}

Individuals eligible for this study were recruited from the institutional review board approved St. Jude Lifetime Cohort Study (SJLIFE). Study details have been reported previously $[18,19]$. Briefly, participants are $\geq 18$ years of age, $\geq 10$ years from their original cancer diagnosis and were treated at St. Jude Children's Research Hospital from 1962-2003. This study is designed to characterize health outcomes among adult survivors of childhood cancer as they age. Detailed treatment information is abstracted from medical records, and participants undergo medical screening based on the Children's Oncology Group Long-Term Follow-Up Guidelines for Survivors of Childhood, Adolescent, and Young Adult Cancers [20]. Screening is augmented by a core battery of medical and laboratory tests, and participants complete surveys that include queries related to psychosocial functioning and health habits. Data for this analysis included information from the baseline survey set; additional information was obtained from a questionnaire about work experiences mailed in the first year after completion of the baseline survey. The first 506 SJLIFE participants who reported ever having a full or part-time job were invited to complete the work experiences survey.

\section{Study Variables}

Career Readiness-Career readiness was measured with the 48-item Career Thoughts Inventory (CTI) [21]. This instrument considers assumptions, attitudes, behaviors, beliefs, plans, and strategies related to career problem solving and decision making. The CTI includes three subscales: 1) Decision Making Confusion, extent to which emotions or lack of decision making skills interfere with ability to make career decisions (14 items); 2) Commitment Anxiety, impact of anxiety on career decision making (10 items); and 3) External Conflict, influence of perceptions of others' opinions/input on career decision making (5 items). The CTI was originally validated in university students [21] with internal reliability coefficients ranging from $0.74-0.94$, and effectively discriminates between persons who do/do not need career counseling. Questions are answered on a four point Likert scale ( $0=$ strongly disagree to $3=$ strongly agree). Scores are summed for each subscale and a global score. Higher scores indicate lower career readiness. Global raw scores were 
converted into T-scores (mean of 50, standard deviation 10), and grouped into three categories: 1) High career readiness, T-score $\leq 54$; 2) Average career readiness, T-score 55-62; and 3) low career readiness, T-score $\geq 63$ [22]. Raw scores on the subscales were used to represent career readiness as a latent construct in analytical models.

Vocational Identity-Vocational identity was assessed with the My Vocational Situation (MVS) instrument [23]. This tool characterizes vocational identity as a person's understanding of career goals, interests, personality and talents. Internal consistencies range from 0.86 to 0.89 . The instrument has been validated in large populations; higher scores indicate more clear and stable vocational identities [23]. Scores are correlated with age, occupational aspirations, educational attainment and employment type [23]. The MVS score was used as a measured variable, potentially associated with career readiness in analytical models.

Emotional Health-Emotional health was evaluated with the Brief Symptom Inventory 18 (BSI-18) [24]. The BSI-18 evaluates mental health globally and across three subscales (depression, somatization, and anxiety). Higher scores indicate higher distress. It has been validated in cancer survivors [25] and population controls and is correlated with the Symptom Checklist-90-Revised $(r=0.93)$. Subscale raw scores were transformed into gender specific T-scores (mean of 50, standard deviation 10). Subscale T-scores were used to indicate the latent construct, emotional health, in analytical models.

Physical Health-The physical function subscale of the Medical Outcomes Survey, Short Form 36 (SF-36), version 2, was used to characterize physical health [26]. The SF-36 is a widely used generic health profile for adults of all ages. It has extensive age- and genderspecific norms for the United States [26], and has been used among adult survivors of childhood cancer [27-29]. The physical function subscale has 10 items that capture abilities to bend, lift, climb stairs, carry items and walk. Lower scores indicate poorer function. Raw scores are transformed into T-scores (mean of 50, standard deviation 10). The physical functioning subscale score was used as a measured variable in analytical models.

Demographic and Treatment Data-Data from medical records were abstracted and used to develop indicators of a latent construct, treatment intensity. Variables were selected because of known or suspected associations with poor neurocognitive outcomes [30]. Exposures were grouped into four ordered categories for cranial radiation, chest radiation, high dose intravenous methotrexate, intrathecal methotrexate and anthracyclines in doxorubicin equivalent doses [31-33]. Demographic data were obtained from questionnaires. Sex, race, current age, age at diagnosis, time since diagnosis, primary cancer diagnosis, income, educational attainment, and type of employment were used to characterize the study population into either low, medium, or high levels of career readiness. A low level of career readiness is indicative of individuals who have a high level of vocational impairment that significantly impacts vocational functioning and creates significant career distress. A medium level of career readiness would indicate a moderate level of vocational impairment that negatively impacts vocational functioning and creates moderate career distress. A high 
level of career readiness indicates no significant vocational impairment and a good ability to make effective career and vocational decisions.

\section{Statistical Methods}

Descriptive statistics were used to characterize the study population. Characteristics of participants and non-participants were compared with two sample t-tests or chi-squared statistics. Based on the theoretical tenets of CIP, individuals with low levels of readiness are at greatest risk for experiencing poor vocational outcomes in contrast to individuals with medium to high levels of readiness. Therefore, differences in participant characteristics comparing those in the low career readiness category to those in the medium or high career readiness category were evaluated with logistic regression and are expressed as odds ratios (OR) and corresponding 95\% confidence intervals (CI).

Subscale scores from the CTI and the BSI, and ordered dose categories for cranial radiation, chest radiation; high dose intravenous methotrexate, intrathecal methotrexate and anthracyclines were evaluated with exploratory factor analysis (EFA) to create latent constructs that represented career readiness, emotional health and treatment intensity for use in structural equation modeling (SEM) [34]. The study population was resampled using a bootstrap procedure [35]; means and 95 percent confidence intervals for standardized factor loadings from 20 iterations were used to determine indicators to retain for each factor. SEM was used to evaluate associations (initial correlation model-Figure 1) between treatment intensity, age at diagnosis, sex, age at survey, emotional and physical health, vocational identity and career readiness [36]. Prior research evaluating vocational constructs in adult survivors of childhood brain tumors has demonstrated significant and meaningful relationships between physical and emotional health, vocational identity and career readiness $[28,29,37,38]$. We included treatment intensity because of its potential effect on cognitive abilities [39.40], likely to impact a survivor's ability to manage career and vocational information. The measurement model (Figure 2) was estimated with confirmatory factor analysis (CFA) and then revised using maximum likelihood; fit statistics, standardized factor loadings, indicator reliabilities, and variance estimates at each revision. Model residuals, and chi-square differences between initial and final models were examined, and specification search methods [41-43] used to determine paths or variables that could be eliminated to achieve a parsimonious final theoretical model (Figure 3) with the best fit.

\section{Results}

Among 506 St. Jude Life Participants who were mailed the work experiences survey, eight were determined ineligible because they were not cognitively capable of completing the survey. Of 498 individuals eligible, 395 (79\%) completed and returned the questionnaire, 81 agreed to participate, but never returned the questionnaire, and 22 declined participation. Ten did not complete the CTI section and were not included in these analyses. Complete treatment data were available for all participants and non-participants. Demographic and treatment characteristics of participants $(\mathrm{N}=385)$ and non-participants $(\mathrm{N}=113)$ are in Table 1. Participants were more likely to be $\geq 30$ year survivors ( $48.3 \%$ versus $36.3 \%$ ) than non- 
participants. Among participants, $76.6 \%$ were currently employed; $28.6 \%$ reported personal incomes of $\$ 40,000$ per year; $42.3 \%$ were college graduates.

Table 2 shows characteristics of the study population by level of Career Readiness and the relative odds of scoring in the low compared to scoring in either the medium or high career readiness categories by characteristics. Unemployed survivors were more likely than those with professional jobs (OR: 2.3, 95\% CI: 1.2-4.5) to have low career readiness. No income (OR: 5.9, 95\% CI: 1.7-20.9), income < $\$ 20,000$ (OR: 4.5, 95\% CI 1.2-17.0), and income $\$ 20-39,000$ per year (OR: 5.2, 95\% CI: 1.5-18.3) were also associated with low career readiness compared to income $\geq \$ 40,000$ per year. Survivors who were not college graduates were 3.0 (95\% CI: 1.6-5.6) times more likely to have low career readiness.

Figure 2 shows the measurement model developed with EFA and CFA. In EFA, subscales of the CTI, the BSI and cranial radiation, chest radiation and intrathecal methotrexate loaded on three factors; standardized factor loadings ranged from 0.46 (95\% CI 0.31-0.61) for treatment intensity and cranial radiation to 0.92 (95\% CI 0.91-0.93) for career readiness and decision making confusion (Table 3) [36]. Neither anthracycline dose or high dose intravenous methotrexate contributed to the treatment intensity construct, so they were excluded from further analysis. CFA indicated that sex and age at survey did not contribute to model fit and that improved fit was obtained by removing covariance estimates between age at diagnosis and vocational identity, career readiness and emotional health, and between treatment intensity and vocational identity, career readiness and emotional health. Four revisions were made to the measurement model to achieve the most parsimonious and best fitting final theoretical model (Figure 3). Fit indices for both the measurement and final theoretical model were all above 0.95 (Table 4). A chi-squared difference test between the final theoretical model and the measurement model was not significant (Chi-square test $=3$, degrees of freedom $=1, \mathrm{p}=0.08$ ), indicating that the final theoretical model provided an excellent fit to the data. This model indicates that associations between treatment intensity, age at diagnosis and physical health and career readiness are mediated by emotional health and vocational identity. Table 5 and Figure 3 show standardized path coefficients for the final model. All coefficients had p-values $<0.20$ and were in the correct direction. Rsquared values showed that $63 \%$ of the variance in career readiness, $35 \%$ of the variance in vocational identity and $10 \%$ of the variance in emotional health were explained by this model.

\section{Discussion}

The aims of this study were to examine career readiness, and evaluate associations between treatment intensity, physical and emotional health, vocational identity and career readiness in childhood cancer survivors. This is the first study we know of to address associations among these variables, as prior research has focused on employment, occupational status and medical risk factors for those outcomes $[1,37,44]$. The results of this study indicate that childhood cancer survivors with low levels of career readiness are more likely to be unemployed, earn $<\$ 40,000$ per year, and be less likely to have graduated from college. Our final theoretical model indicates that vocational identity and emotional health account for 
the indirect effect of treatment intensity, age at diagnosis, and physical health on career readiness.

Our first aim was to examine differences between levels of career readiness across demographic and treatment variables. We found differences for unemployment status, educational attainment and personal income. Despite limited prior research in this area, our findings are consistent with the theory that individuals with lower levels of career readiness are less likely to have clear career thoughts or experience success in educational and career situations [17]. The finding that higher educational attainment is associated with more developed vocational identity has not been examined in other studies but has face validity and is consistent with current vocational theory [45]. Survivors with low career readiness experience lower wages indicating underemployment may be an issue among survivors like it is in other populations. Individuals with disabilities and chronic health conditions are at risk for underemployment, working in positions with low wages and few benefits [46]. Theoretically, being underemployed and working in entry level positions with low wages and few benefits could contribute to decreased vocational identity and career readiness. Underemployment has been linked to negative affective and behavioral states such as anxiety, decreased autonomy, decreased self-determination, dependence, and uncertainty regarding employment future. Persons who are underemployed often express concerns regarding their abilities to earn an adequate wage and gain access to health care [47].

Our second aim examined associations among treatment intensity, age at diagnosis, physical health, poor emotional health, higher vocational identity, and lower career readiness among childhood cancer survivors. Utilizing SEM, we found that treatment intensity, age at diagnosis, and physical health had indirect influences on career readiness through emotional health and vocational identity. Specifically, better physical health was correlated with better emotional health, which in turn correlated with more clear and stable vocational identity. In addition, diagnosis at older ages was related to clear vocational identity, which in turn correlated with higher career readiness. This result is consistent with vocational psychology studies that identify strong associations between vocational identity and career readiness [48]. Consistent with our findings, previous work [16] indicates that individuals who report higher levels of anxiety and depression have lower levels of career readiness (measured by the CTI). In a recent study by Bullock et al [47], higher levels of emotional instability were associated with lower levels of career readiness. Overall, the results of this analysis are theoretically consistent with the basic tenets of the CIP framework indicating that career readiness is impacted by an individual's emotional state (complexity and capability) and his or her level of vocational identity. The results also point to the need to modify and expand the CIP framework when working with cancer survivors to address issues related to age at diagnosis, treatment intensity, and physical health, issues that are not typically addressed in vocational psychology theory or research, as they appear to indirectly impact emotional health and vocational identity.

Prior studies among childhood cancer survivors indicate that work limitations are problematic in CNS tumor survivors, those exposed to cranial radiotherapy, and survivors diagnosed at younger age, primarily because of late effects involving musculoskeletal and neurological systems $[1,40,41]$. In our study, we found that survivors diagnosed at younger 
age, exposed to higher levels of cranial and chest radiotherapy or intrathecal methotrexate reported poor vocational identity and career readiness. Although age at diagnosis and treatment intensity are not variables that can be altered post-therapy, results indicate that survivors younger at diagnosis and who are exposed to intense treatment are at risk for low career readiness and should be targeted for intervention. Specifically, individuals who receive high doses of radiation to the brain or chest or who are treated with intrathecal methotrexate may be more likely to experience lower levels of career readiness and may have a greater need for vocational interventions. This would appear to be an important area that needs to be addressed in future research. Our results also indicate that interventions to improve employment outcomes for childhood cancer survivors should include evaluation and remediation for physical and emotional health issues and be directed at enhancing survivors' understanding of their career goals, interests, personality and talents. Even though evidence suggests that increasing vocational identity and career readiness facilitates career development in other populations, career or vocational counseling is not typical as part of post-acute cancer treatment despite known employment issues in childhood cancer survivors.

\section{Limitations}

There are limitations that should be considered while interpreting the results of this study. First, the data collected is limited to a single institution with limited racial variability and thus, may not generalizable to the broader childhood cancer survivor population. Second, measures on vocational identity and career readiness were based on self-reported data that cannot be cross-validated by independent observation or review of objective records. Third, the data were cross-sectional and thus limit the ability to determine causal associations among variables. Fourth, we limited our study sample to survivors who had ever been employed, and although $94.8 \%$ of survivors in our cohort reported ever having a job, our results cannot be generalized to survivors who have never been employed. Finally, for this study no data was obtained from any siblings or non-cancer survivors, which precludes any between group analyses on relevant demographic variables.

\section{Clinical Implications}

Results of this study provide initial support for the inclusion of career and vocational services as part of follow-up for childhood cancer survivors. Interventions to improve employment outcomes should not only focus on physical health, neurocognitive problems, and screening for mental health issues, but should also address vocational and career readiness to maximize employment potential.

\section{Acknowledgements}

This study was funded by: Cancer Center Support (CORE) grant CA 21765 from the National Cancer Institute and by the American Lebanese Syrian Associated Charities (ALSAC)

\section{References}

1. Pang JWY, Friedman DL, Whitton JA, Stovall M, Mertens AC, Robison LL, et al. Employment status among adult survivors in the Childhood Cancer Survivor Study. Pediatr Blood Cancer. 2008; 50(1):104-10. [PubMed: 17554791] 
2. Kirchhoff AC, Leisenring W, Krull KR, Ness KK, Friedman DL, Armstrong GT, et al. Unemployment among adult survivors of childhood cancer: a report from the Childhood Cancer Survivor Study. Medical Care. 2010; 48(11):1015-25. [PubMed: 20940653]

3. Stern M, Krivoy E, Foster RH, Bitsko M, Toren A, Ben-Arush M. Psychosocial functioning and career decision - making in Israeli adolescent and young adult cancer survivors. Pediatric Blood \& Cancer. 2010; 55(4):708-13. [PubMed: 20589658]

4. Stern M, Norman SL, Zevon MA. Career development of adolescent cancer patients: A comparative analysis. Journal of counseling psychology. 1991; 38(4):431-9.

5. de Boer AGEM, Verbeek JHAM, van Dijk FJH. Adult survivors of childhood cancer and unemployment. Cancer. 2006; 107(1):1-11. [PubMed: 16718655]

6. de Boer AGEM, Taskila T, Ojajarvi A, van Dijk FJH, verbeek JHAM. Cancer survivors and unemployment: a meta-analysis and meta-regression. JAMA. 2009; 301(7):753-62. [PubMed: 19224752]

7. Ness KK, Gurney JG, Zeltzer LK, Leisenring W, Mulrooney DA, Nathan PC, et al. The impact of limitations in physical, executive, and emotional function on health-related quality of life among adult survivors of childhood cancer: A report from the Childhood Cancer Survivor Study. Arch Phys Med Rehab. 2008; 89(1):128-36.

8. Ness KK, Wall MM, Oakes JM, Robison LL, Gurney JG. Physical performance limitations and participation restrictions among cancer survivors: a population-based study. Ann Epidemiol. 2006; 16(3):197-205. [PubMed: 16137893]

9. Strauser D, Wagner S, Wong AWK, O'Sullivan D. Career readiness, developmental work personality and age of onset in young adult central nervous system survivors. Disabil Rehabil. 2013; 35(7):543-50. [PubMed: 22891646]

10. Gottfredson, LS. Gottfredson's theory of circumscription, compromise, and self-creation.. In: Brown, D., editor. Career Choice and Development. Jossey-Bass; San Francisco, CA: 2002. p. 85-148.

11. Super, DE. The Psychology of Careers: An Introduction to Vocational Development. Harper \& Brothers; New York, NY: 1957.

12. Vondracek, FW.; Lerner, RM.; Schulenberg, JE. Career Development: A Life-Span Developmental Approach. Erlbaum Associates; Hillsdale, NJ.: 1986.

13. Short PF, Vasey JJ, Tunceli K. Employment pathways in a large cohort of adult cancer survivors. Cancer. 2005; 103(6):1292-301. [PubMed: 15700265]

14. Peterson, GW.; Sampson, JP., Jr; Reardon, RC. Career Development and Services: A Cognitive Approach. Thomson Brooks/Cole Publishing Co.; Pacific Grove, CA: 1991.

15. Sampson, JP. Career Counseling and Services: A Cognitive Information Processing Approach. Thomson/Brooks/Cole; Belmont, CA: 2004.

16. Saunders DE, Peterson GW, Sampson JP Jr, Reardon RC. Relation of depression and dysfunctional career thinking to career indecision. Journal of Vocational Behavior. 2000; 56(2):288-98.

17. Strauser D, Zanskas S, Lustig D. Career readiness and individuals with disabilities. Rehabil Res Edu Pol. 2011; 25(3-4):173-9.

18. Hudson MM, Ness KK, Nolan VG, Armstrong GT, Green DM, Morris EB, et al. Prospective medical assessment of adults surviving childhood cancer: Study design, cohort characteristics, and feasibility of the St. Jude Lifetime Cohort study. Pediatric Blood \& Cancer. 2011; 56:825-36. [PubMed: 21370418]

19. Ojha RP, Oancea SC, Ness KK, Lanctot JQ, Srivastava DK, Robison LL, et al. Assessment of potential bias from non-participation in a dynamic clinical cohort of long-term childhood cancer survivors: results from the St. Jude Lifetime Cohort Study. Pediatr Blood Cancer. 2013; 60(5): 856-64. [PubMed: 23024097]

20. Landier W, Bhatia S, Eshelman DA, Forte KJ, Sweeney T, Hester AL, et al. Development of riskbased guidelines for pediatric cancer survivors: the Children's Oncology Group Long-term Followup Guidelines from the Children's Oncology Group Late Effects Committee and Nursing Discipline. Journal of Clinical Oncology. 2004; 22(24):4979-90. [PubMed: 15576413]

21. Sampson, JP. Career Thoughts Inventory: Professional Manual. Psychological Assessment Resources, Inc.; Odessa, FL: 1996. 
22. Sampson JP, Peterson GW, Lenz JG, Reardon RC, Saunders DE. The design and use of a measure of dysfunctional career thoughts among adults, college students, and high school students: The Career Thoughts Inventory. Journal of Career Assessment. 1998; 6(2):115-34.

23. Holland, JL.; Daiger, DC.; Power, PG.; Press, CP. My Vocational Situation. Consulting Psychologists Press; Palo Alto, CA: 1980.

24. Derogatis, LR. BSI-18: Administration, Scoring and Procedures Manual. NCS Pearson, Inc.; Minneapolis, MN: 2000.

25. Recklitis CJ, Parsons SK, Shih MC, Mertens A, Robison LL, Zeltzer L. Factor structure of the Brief Symptom Inventory-18 in adult survivors of childhood cancer: Results from the Childhood Cancer Survivor Study. Psychological Assessment. 2006; 18(1):22-32. [PubMed: 16594809]

26. Ware JE Jr, Sherbourne CD. The MOS 36-item short-form health survey (SF-36): I. Conceptual framework and item selection. Medical Care. 1992; 30(6):473-83. [PubMed: 1593914]

27. Reulen RC, Zeegers MP, Jenkinson C, Lancashire ER, Winter DL, Jenney ME, et al. The use of the SF-36 questionnaire in adult survivors of childhood cancer: evaluation of data quality, score reliability, and scaling assumptions. Health Quality Life Outcomes. 2006; 4(10):77-88.

28. Zeltzer LK, Lu Q, Leisenring W, Tsao JC, Recklitis C, Armstrong G, et al. Psychosocial outcomes and health-related quality of life in adult childhood cancer survivors: a report from the childhood cancer survivor study. Cancer Epidemiology Biomarkers \& Prevention. 2008; 17(2):435-46.

29. Zeltzer LK, Recklitis C, Buchbinder D, Zebrack B, Casillas J, Tsao JC, et al. Psychological status in childhood cancer survivors: a report from the Childhood Cancer Survivor Study. Journal of Clinical Oncology. 2009; 27(14):2396-404. [PubMed: 19255309]

30. Winick N. Neurocognitive outcome in survivors of pediatric cancer. Current opinion in pediatrics. 2011; 23(1):27-33. [PubMed: 21157347]

31. Allen A. The cardiotoxicity of chemotherapeutic drugs. Seminars in oncology. 1992; 19(5):529_ 42. [PubMed: 1411651]

32. Launchbury AP, Habboubi N. Epirubicin and doxorubicin: a comparison of their characteristics, therapeutic activity and toxicity. Cancer treatment reviews. 1993; 19(3):197-228. [PubMed: 8334677]

33. Tolba KA, Deliargyris EN. Cardiotoxicity of cancer therapy. Cancer investigation. 1999; 17(6): 408-22. [PubMed: 10434952]

34. Hatcher, L. A Step-by Step Approach to Using SAS for Factor Analysis and Structural Equation Modeling. SAS Institute Inc; Cary, NC: 1994.

35. Efron, B.; Tibshirani, RJ. An Introduction to the Bootstrap. CRC Press; Boca Raton, FL: 1994.

36. Anderson JC, Gerbing DW. Structural equation modeling in practice: A review and recommended two-step approach. Psychological bulletin. 1988; 103(3):411-23.

37. Kirchhoff AC, Krull KR, Ness KK, Armstron GT, Park ER, Stovall M, et al. Physical, mental and neurocognitive status and employment outcomes in the childood cance survivor study cohort. Cancer Epidemiol Biomarkers. 2011; 20(9):1838-49.

38. Steiner JF, Cavender TA, Main DS, Bradley CJ. Assessing the impact of cancer on work outcomes. Cancer. 2004:1703-11. 101*8. [PubMed: 15386303]

39. Buizer AJ, de Sonneville LM, van den Heuvel-Eibrink MM, Veerman AJ. Chemotherapy and attentional dysfunction in survivors of childhood acute lymphoblastic leukemia: effect of treatment intensity. Pediatr Blood Cancer. 2005; 45(3):281-90. [PubMed: 15806539]

40. van Dam FS, Boogerd W, Schagen SB, Muller MJ, Fortuyn MED, vd Wall E, et al. Impairment of cognitive function in women receiving adjuvant treatment for high-risk breast cancer: high-dose versus standard-dose chemotherapy. J Natl Cancer I. 1998; 90(3):210-8.

41. MacCallum RC, Roznowski M, Necowitz LB. Model modifications in covariance structure analysis: The problem of capitalization on chance. Psychological bulletin. 1992; 111(3):490-504. [PubMed: 16250105]

42. Bentler PM, Chou CP. Practical issues in structural modeling. Sociological Methods \& Research. 1987; 16(1):78-117.

43. Bentler PM. Comparative fit indexes in structural models. Psychological bulletin. 1990; 107(2): 238-46. [PubMed: 2320703] 
44. Kirchhoff AC, Krull KR, Ness KK, Park ER, Oeffinger KC, Hudson MM, et al. Occupational outcomes of adult childhood cancer survivors: A report from the Childhood Cancer Survivor Study. Cancer. 2011; 117(13):3033-44. [PubMed: 21246530]

45. Holland, JL. Making Vocatinal Choices: A Theory of Vocational Personalities and Work Environments. Psychological Assessment Resources; Odessa, FL: 1997.

46. Lustig DC, Strauser DR. Health benefits for vocational rehabilitation consumers: Comparison of access rates with workers in the general population. Rehabilitation Counseling Bulletin. 2010; 53(2):87-95.

47. Blustein DL. The role of work in psychological health and well-being. American Psychologist. 2008; 63(4):228-40. [PubMed: 18473608]

48. Sampson, J., Jr; Peterson, G.; Lenz, J.; Reardon, R.; Saunders, D. Improving Your Career Thoughts: A Workbook for the Career Thoughts Inventory. Psychological Assessment Resources; Odessa, FL: 1996. 


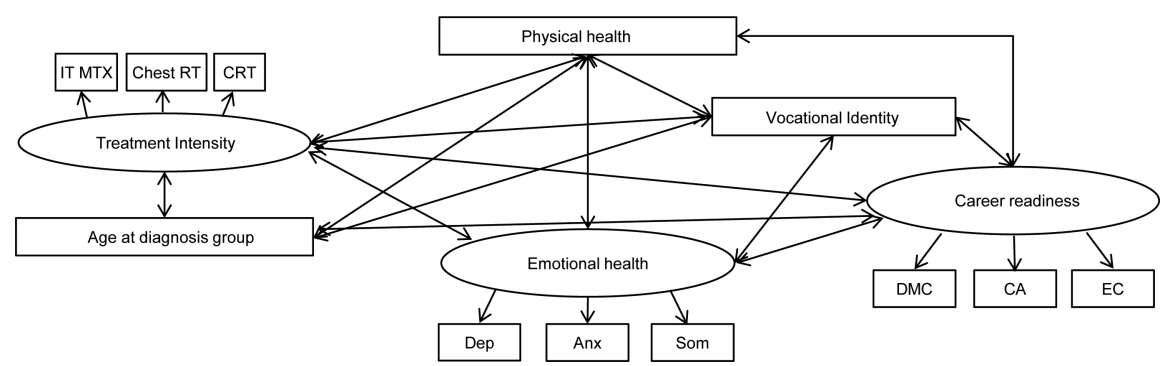

Figure 1.

Initial Correlation Model 


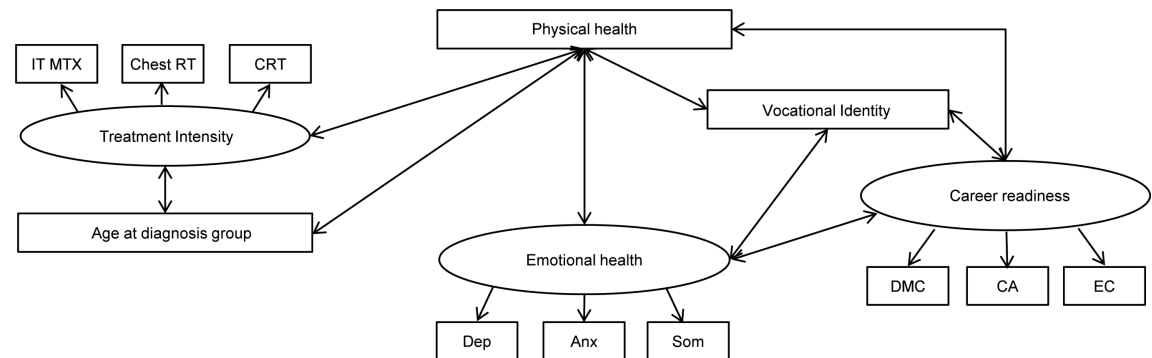

Figure 2.

Final Measurement Model 


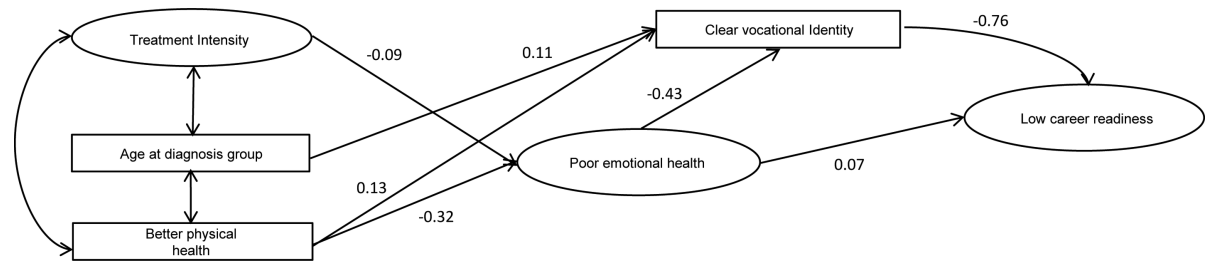

Figure 3.

Final Theoretical Model 
Table 1

Demographic and treatment characteristics of the participants and non-participants

\begin{tabular}{|c|c|c|c|c|c|}
\hline & \multicolumn{2}{|c|}{ Participants ( $\mathrm{N}=\mathbf{3 8 5}$ ) } & \multicolumn{2}{|c|}{ Non-participants $(\mathrm{N}=113)$} & \multirow[t]{2}{*}{ p-value } \\
\hline & $\mathbf{N}$ & $\%$ & $\mathbf{N}$ & $\%$ & \\
\hline \multicolumn{6}{|l|}{ Sex } \\
\hline Male & 162 & $(42.08)$ & 56 & $(49.56)$ & 0.15 \\
\hline Female & 223 & $(57.92)$ & 57 & $(50.44)$ & \\
\hline \multicolumn{6}{|l|}{ Race } \\
\hline White & 347 & (90.13) & 104 & (92.04) & 0.79 \\
\hline Non-white & 38 & $(9.87)$ & 9 & (7.96) & \\
\hline \multicolumn{6}{|l|}{ Diagnosis } \\
\hline Leukemia & 205 & $(53.25)$ & 65 & $(57.52)$ & 0.08 \\
\hline Lymphoma & 96 & $(24.94)$ & 16 & (14.16) & \\
\hline Bone or soft tissue sarcoma & 43 & (11.17) & 20 & $(17.70)$ & \\
\hline Neuroblastoma & 15 & $(3.90)$ & 7 & $(6.19)$ & \\
\hline Wilms tumor & 14 & $(3.64)$ & 2 & $(1.77)$ & \\
\hline Other & 12 & $(3.12)$ & 3 & $(2.65)$ & \\
\hline \multicolumn{6}{|l|}{ Age at diagnosis } \\
\hline $0-4$ years & 129 & (33.51) & 43 & (38.05) & 0.19 \\
\hline $5-9$ years & 102 & $(26.49)$ & 36 & $(31.86)$ & \\
\hline $10-14$ years & 80 & (20.78) & 14 & (12.39) & \\
\hline $15-20$ years & 74 & $(19.22)$ & 20 & $(17.70)$ & \\
\hline \multicolumn{6}{|l|}{ Age at questionnaire } \\
\hline $18-24$ years & 19 & $(4.94)$ & 8 & $(7.08)$ & 0.06 \\
\hline $25-29$ years & 49 & (12.73) & 22 & (19.47) & \\
\hline $30-34$ years & 58 & (15.06) & 21 & (18.58) & \\
\hline $35-39$ years & 95 & (24.68) & 26 & $(23.01)$ & \\
\hline $40-44$ years & 92 & $(23.90)$ & 27 & (23.89) & \\
\hline $45+$ years & 72 & $(18.70)$ & 9 & (7.96) & \\
\hline \multicolumn{6}{|l|}{ Time since diagnosis } \\
\hline $10-19$ years & 41 & (10.65) & 9 & $(7.96)$ & 0.02 \\
\hline $20-29$ years & 158 & (41.04) & 63 & $(55.75)$ & \\
\hline $30+$ years & 186 & $(48.31)$ & 41 & $(36.28)$ & \\
\hline \multicolumn{6}{|l|}{ Cranial radiation } \\
\hline None & 221 & $(57.40)$ & 64 & $(56.64)$ & 0.7 \\
\hline $1-23 \mathrm{~Gy}$ & 58 & (15.06) & 13 & $(11.50)$ & \\
\hline $24 \mathrm{~Gy}$ & 87 & $(22.60)$ & 29 & (25.66) & \\
\hline $25+\mathrm{Gy}$ & 19 & $(4.94)$ & 7 & $(6.19)$ & \\
\hline \multicolumn{6}{|l|}{ Chest radiation } \\
\hline None & 286 & (74.29) & 89 & (78.76) & 0.77 \\
\hline 1-19 Gy & 18 & $(4.68)$ & 5 & $(4.42)$ & \\
\hline 20-29 Gy & 29 & (7.53) & 6 & $(5.31)$ & \\
\hline
\end{tabular}




\begin{tabular}{|c|c|c|c|c|c|}
\hline & \multicolumn{2}{|c|}{ Participants $(\mathrm{N}=\mathbf{3 8 5})$} & \multicolumn{2}{|c|}{ Non-participants $(\mathrm{N}=113)$} & \multirow[t]{2}{*}{ p-value } \\
\hline & $\mathbf{N}$ & $\%$ & $\mathbf{N}$ & $\%$ & \\
\hline $30+\mathrm{Gy}$ & 52 & $(13.51)$ & 13 & $(11.50)$ & \\
\hline \multicolumn{6}{|l|}{ High dose Intravenous methotrexate } \\
\hline None & 301 & (78.18) & 81 & $(71.68)$ & 0.21 \\
\hline $1-9,999 \mathrm{mg} / \mathrm{m}^{2}$ & 33 & $(8.57)$ & 13 & $(11.50)$ & \\
\hline $10,000-29,999 \mathrm{mg} / \mathrm{m}^{2}$ & 34 & $(8.83)$ & 9 & (7.96) & \\
\hline $30,000+\mathrm{mg} / \mathrm{m}^{2}$ & 17 & $(4.42)$ & 10 & $(8.85)$ & \\
\hline \multicolumn{6}{|l|}{ Intrathecal methotrexate } \\
\hline None & 191 & $(49.61)$ & 54 & $(47.79)$ & 0.76 \\
\hline $1-99 \mathrm{mg} / \mathrm{m}^{2}$ & 84 & $(21.82)$ & 24 & $(21.24)$ & \\
\hline $100-249 \mathrm{mg} / \mathrm{m}^{2}$ & 87 & $(22.60)$ & 25 & $(22.12)$ & \\
\hline $250+\mathrm{mg} / \mathrm{m}^{2}$ & 23 & $(5.97)$ & 10 & $(8.85)$ & \\
\hline \multicolumn{6}{|l|}{ Anthracyclines } \\
\hline None & 148 & $(38.44)$ & 40 & $(35.40)$ & 0.59 \\
\hline $1-99 \mathrm{mg} / \mathrm{m}^{2}$ & 82 & $(21.30)$ & 25 & $(22.12)$ & \\
\hline $100-349 \mathrm{mg} / \mathrm{m}^{2}$ & 98 & $(25.45)$ & 35 & $(30.97)$ & \\
\hline $350+\mathrm{mg} / \mathrm{m}^{2}$ & 57 & $(14.81)$ & 13 & $(11.50)$ & \\
\hline \multicolumn{6}{|l|}{ Employment status } \\
\hline Unemployed & 90 & $(23.38)$ & & & \\
\hline Professional & 162 & $(42.08)$ & & & \\
\hline Service Worker & 73 & (18.96) & & & \\
\hline Production/construction/outdoor work & 60 & $(15.58)$ & & & \\
\hline \multicolumn{6}{|l|}{ Personal income } \\
\hline None & 90 & $(23.38)$ & & & \\
\hline$<\$ 20,000 /$ year & 56 & (14.55) & & & \\
\hline$\$ 20-39.000 /$ year & 95 & $(24.68)$ & & & \\
\hline$\$ 40-59.000 /$ year & 52 & $(13.51)$ & & & \\
\hline$\$ 60,000+/$ year & 58 & $(15.06)$ & & & \\
\hline \multicolumn{6}{|l|}{ Educational attainment } \\
\hline College graduate & 163 & $(42.34)$ & & & \\
\hline Not a college graduate & 222 & $(57.66)$ & & & \\
\hline
\end{tabular}

$\mathrm{Gy}=\mathrm{Gray}, \mathrm{mg} / \mathrm{m}^{2}=$ milligrams per meter squared 
Table 2

Characteristics of the study population by level of career readiness with odds ratios and $95 \%$ confidence intervals for scoring in the low category compared to scoring in the medium or high career readiness category

\begin{tabular}{|c|c|c|c|c|c|c|c|c|c|}
\hline & & \multicolumn{8}{|c|}{ Career Readiness Category } \\
\hline & & \multicolumn{2}{|c|}{$\operatorname{Low}^{a} \mathrm{~N}=67$} & \multicolumn{2}{|c|}{$\operatorname{Medium}^{a} \mathrm{~N}=110$} & \multicolumn{2}{|c|}{$\operatorname{High}^{a} \mathrm{~N}=208$} & \multirow[b]{2}{*}{ OR } & \multirow[b]{2}{*}{$95 \% \mathrm{CI}$} \\
\hline & & $\mathbf{N}$ & $\%$ & $\mathbf{N}$ & $\%$ & $\mathbf{N}$ & $\%$ & & \\
\hline \multicolumn{10}{|l|}{ Sex } \\
\hline Male & 162 & 28 & (17.28) & 45 & (27.78) & 89 & $(54.94)$ & 1.0 & \\
\hline Female & 223 & 39 & (17.49) & 65 & $(29.15)$ & 119 & $(53.36)$ & 1.0 & $0.6-1.7$ \\
\hline \multicolumn{10}{|l|}{ Race } \\
\hline White & 347 & 56 & $(16.14)$ & 102 & $(29.39)$ & 189 & $(54.47)$ & 1.0 & \\
\hline Non-white & 38 & 11 & $(28.95)$ & 8 & $(21.05)$ & 19 & $(50.00)$ & 2.1 & $1.0-4.5$ \\
\hline \multicolumn{10}{|l|}{ Diagnosis } \\
\hline Leukemia & 205 & 37 & $(18.05)$ & 64 & $(31.22)$ & 104 & $(50.73)$ & 1.0 & \\
\hline Lymphoma & 96 & 19 & $(19.79)$ & 23 & $(23.96)$ & 54 & $(56.25)$ & 1.1 & $0.6-2.1$ \\
\hline Bone or soft tissue sarcoma & 43 & 3 & $(6.98)$ & 16 & $(37.21)$ & 24 & $(55.81)$ & 0.3 & $0.1-1.2$ \\
\hline Neuroblastoma & 15 & 5 & (33.33) & 1 & $(6.67)$ & 9 & $(60.00)$ & 2.3 & $0.7-7.0$ \\
\hline Wilms tumor & 14 & 1 & $(7.14)$ & 4 & $(28.57)$ & 9 & $(64.29)$ & 0.3 & $0.1-2.8$ \\
\hline Other & 12 & 2 & (16.67) & 2 & $(16.67)$ & 8 & $(66.67)$ & 0.9 & $0.2-4.3$ \\
\hline \multicolumn{10}{|l|}{ Age at diagnosis } \\
\hline $0-4$ years & 129 & 25 & (19.38) & 40 & $(31.01)$ & 64 & $(49.61)$ & 1.2 & $0.6-2.6$ \\
\hline $5-9$ years & 102 & 18 & $(17.65)$ & 32 & $(31.37)$ & 52 & $(50.98)$ & 1.1 & $0.5-2.5$ \\
\hline $10-14$ years & 80 & 12 & $(15.00)$ & 17 & $(21.25)$ & 51 & $(63.75)$ & 0.9 & $0.4-2.2$ \\
\hline $15-20$ years & 74 & 12 & $(16.22)$ & 21 & $(28.38)$ & 41 & $(55.41)$ & 1.0 & \\
\hline \multicolumn{10}{|l|}{ Age at questionnaire } \\
\hline $18-24$ years & 19 & 5 & $(26.32)$ & 3 & (15.79) & 11 & $(57.89)$ & 2.6 & $0.7-9.5$ \\
\hline $25-29$ years & 49 & 10 & $(20.41)$ & 13 & $(26.53)$ & 26 & $(53.06)$ & 1.9 & $0.7-5.3$ \\
\hline $30-34$ years & 58 & 7 & (12.07) & 21 & $(36.21)$ & 30 & $(51.72)$ & 1.0 & \\
\hline $35-39$ years & 95 & 18 & (18.95) & 22 & (23.16) & 55 & $(57.89)$ & 1.7 & $0.7-4.4$ \\
\hline $40-44$ years & 92 & 16 & (17.39) & 31 & $(33.70)$ & 45 & $(48.91)$ & 1.5 & $0.6-4.0$ \\
\hline $45+$ years & 72 & 11 & (15.28) & 20 & (27.78) & 41 & (56.94) & 1.3 & $0.5-3.6$ \\
\hline \multicolumn{10}{|l|}{ Time since diagnosis } \\
\hline $10-19$ years & 41 & 4 & $(9.76)$ & 9 & (21.95) & 28 & $(68.29)$ & 0.5 & $0.2-1.6$ \\
\hline $20-29$ years & 158 & 31 & $(19.62)$ & 43 & $(27.22)$ & 84 & $(53.16)$ & 1.2 & $0.7-2.0$ \\
\hline $30+$ years & 186 & 32 & $(17.20)$ & 58 & $(31.18)$ & 96 & $(51.61)$ & 1.0 & \\
\hline \multicolumn{10}{|l|}{ Cranial radiation } \\
\hline None & 221 & 37 & $(16.74)$ & 62 & $(28.05)$ & 122 & $(55.20)$ & 1.0 & \\
\hline $1-23$ Gy & 58 & 13 & $(22.41)$ & 10 & $(17.24)$ & 35 & $(60.34)$ & 1.4 & $0.7-2.9$ \\
\hline $24 \mathrm{~Gy}$ & 87 & 13 & (14.94) & 32 & $(36.78)$ & 42 & $(48.28)$ & 0.9 & $0.4-1.7$ \\
\hline $25+\mathrm{Gy}$ & 19 & 4 & $(21.05)$ & 6 & $(31.58)$ & 9 & $(47.37)$ & 1.3 & $0.4-4.2$ \\
\hline \multicolumn{10}{|l|}{ Chest radiation } \\
\hline None & 286 & 49 & (17.13) & 88 & (30.77) & 149 & $(52.10)$ & 1.0 & \\
\hline
\end{tabular}




\begin{tabular}{|c|c|c|c|c|c|c|c|c|c|}
\hline & & \multicolumn{8}{|c|}{ Career Readiness Category } \\
\hline & & \multicolumn{2}{|c|}{$\operatorname{Low}^{a} \mathrm{~N}=67$} & \multicolumn{2}{|c|}{$\operatorname{Medium}^{a} \mathrm{~N}=110$} & \multicolumn{2}{|c|}{$\operatorname{High}^{a} \mathrm{~N}=208$} & \multirow[b]{2}{*}{ OR } & \multirow[b]{2}{*}{$95 \% \mathrm{CI}$} \\
\hline & & $\mathbf{N}$ & $\%$ & $\mathbf{N}$ & $\%$ & $\mathbf{N}$ & $\%$ & & \\
\hline 1-19 Gy & 18 & 4 & $(22.22)$ & 1 & $(5.56)$ & 13 & $(72.22)$ & 1.4 & $0.4-4.4$ \\
\hline $20-29$ Gy & 29 & 4 & $(13.79)$ & 7 & $(24.14)$ & 18 & $(62.07)$ & 0.8 & $0.3-2.3$ \\
\hline $30+\mathrm{Gy}$ & 52 & 10 & $(19.23)$ & 14 & $(26.92)$ & 28 & $(53.85)$ & 1.2 & $0.5-2.5$ \\
\hline \multicolumn{10}{|l|}{ High dose Intravenous methotrexate } \\
\hline None & 301 & 54 & $(17.94)$ & 84 & $(27.91)$ & 163 & $(54.15)$ & 1.0 & \\
\hline $1-9,999 \mathrm{mg} / \mathrm{m}^{2}$ & 33 & 7 & $(21.21)$ & 9 & $(27.27)$ & 17 & $(51.52)$ & 1.2 & $0.5-3.0$ \\
\hline $10,000-29,999 \mathrm{mg} / \mathrm{m}^{2}$ & 34 & 4 & $(11.76)$ & 12 & $(35.29)$ & 18 & $(52.94)$ & 0.6 & $0.2-1.8$ \\
\hline $30,000+\mathrm{mg} / \mathrm{m}^{2}$ & 17 & 2 & $(11.76)$ & 5 & $(29.41)$ & 10 & $(58.82)$ & 0.6 & $0.1-2.7$ \\
\hline \multicolumn{10}{|l|}{ Intrathecal methotrexate } \\
\hline None & 191 & 31 & $(16.23)$ & 47 & $(24.61)$ & 113 & $(59.16)$ & 1.0 & \\
\hline $1-99 \mathrm{mg} / \mathrm{m}^{2}$ & 84 & 15 & $(17.86)$ & 29 & $(34.52)$ & 40 & $(47.62)$ & 1.1 & $0.6-2.2$ \\
\hline $100-249 \mathrm{mg} / \mathrm{m}^{2}$ & 87 & 16 & $(18.39)$ & 24 & $(27.59)$ & 47 & $(54.02)$ & 1.2 & $0.6-2.3$ \\
\hline $250+\mathrm{mg} / \mathrm{m}^{2}$ & 23 & 5 & $(21.74)$ & 10 & $(43.48)$ & 8 & $(34.78)$ & 1.4 & $0.5-4.2$ \\
\hline \multicolumn{10}{|l|}{ Anthracyclines } \\
\hline None & 148 & 27 & $(18.24)$ & 41 & $(27.70)$ & 80 & $(54.05)$ & 1.0 & \\
\hline $1-99 \mathrm{mg} / \mathrm{m}^{2}$ & 82 & 14 & $(17.07)$ & 25 & $(30.49)$ & 43 & $(52.44)$ & 0.9 & $0.5-1.9$ \\
\hline $100-349 \mathrm{mg} / \mathrm{m}^{2}$ & 98 & 21 & $(21.43)$ & 26 & $(26.53)$ & 51 & $(52.04)$ & 1.2 & $0.6-2.3$ \\
\hline $350+\mathrm{mg} / \mathrm{m}^{2}$ & 57 & 5 & $(8.77)$ & 18 & $(31.58)$ & 34 & $(59.65)$ & 0.4 & $0.2-1.2$ \\
\hline \multicolumn{10}{|l|}{ Employment status } \\
\hline Unemployed & 90 & 22 & $(24.44)$ & 31 & $(34.44)$ & 37 & $(41.11)$ & 2.3 & $1.2-4.5$ \\
\hline Professional & 162 & 20 & $(12.35)$ & 36 & $(22.22)$ & 106 & $(65.43)$ & 1.0 & \\
\hline Service Worker & 73 & 13 & $(17.81)$ & 24 & $(32.88)$ & 36 & $(49.32)$ & 1.5 & $0.7-3.3$ \\
\hline Production/construction/outdoor work & 60 & 12 & $(20.00)$ & 19 & $(31.67)$ & 29 & $(48.33)$ & 1.8 & $0.8-3.9$ \\
\hline \multicolumn{10}{|l|}{ Personal income } \\
\hline None & 90 & 22 & (24.44) & 31 & $(34.44)$ & 37 & $(41.11)$ & 5.9 & $1.7-20.9$ \\
\hline$<\$ 20,000 /$ year & 56 & 11 & (19.64) & 19 & $(33.93)$ & 26 & $(46.43)$ & 4.5 & $1.2-17.0$ \\
\hline$\$ 20-39,000 /$ year & 95 & 21 & $(22.11)$ & 28 & $(29.47)$ & 46 & $(48.42)$ & 5.2 & $1.5-18.3$ \\
\hline$\$ 40-59,000 /$ year & 52 & 4 & (7.69) & 13 & $(25.00)$ & 35 & $(67.31)$ & 1.5 & $0.3-7.2$ \\
\hline$\$ 60,000+/$ year & 58 & 3 & $(5.17)$ & 10 & (17.24) & 45 & (77.59) & 1.0 & \\
\hline \multicolumn{10}{|l|}{ Educational attainment } \\
\hline College graduate & 163 & 15 & $(9.20)$ & 32 & (19.63) & 116 & (71.17) & 1.0 & \\
\hline Not a college graduate & 222 & 52 & (23.42) & 78 & (35.14) & 93 & (41.89) & 3.0 & $1.6-5.6$ \\
\hline
\end{tabular}

${ }^{a}$ Career readiness: low, T-score $\varangle 3$; medium, T-score 55-62; high T-score $54, \mathrm{~Gy}=\mathrm{Gray}, \mathrm{mg} / \mathrm{m}^{2}=$ milligrams per meter squared, OR=Odds ratio, $\mathrm{CI}=$ Confidence Interval 
Table 3

Results of cxploratory factor analysis used to created latent constructs for the structural equation model

\begin{tabular}{lc}
\hline Construct and indicators & Standardized Factor Loading (95\% CI) \\
Career Thoughts & $0.92(0.91-0.93)$ \\
Decision Making Confusion & $0.88(0.87-0.89)$ \\
Commitment Anxiety & $0.83(0.82-0.84)$ \\
External Conflict & \\
Emotional Health & $0.78(0.76-0.79)$ \\
Depression & $0.92(0.91-0.94)$ \\
Anxiety & $0.65(0.63-0.67)$ \\
Somatization & \\
Treatment intensity & $0.56(0.37-0.75)$ \\
Intrathecal methotrexate dose group & $0.46(0.31-0.61)$ \\
Cranial radiation dose group & $0.51(0.31-0.71)$ \\
Chest radiation dose group & \\
\hline
\end{tabular}

CI=Confidence interval 


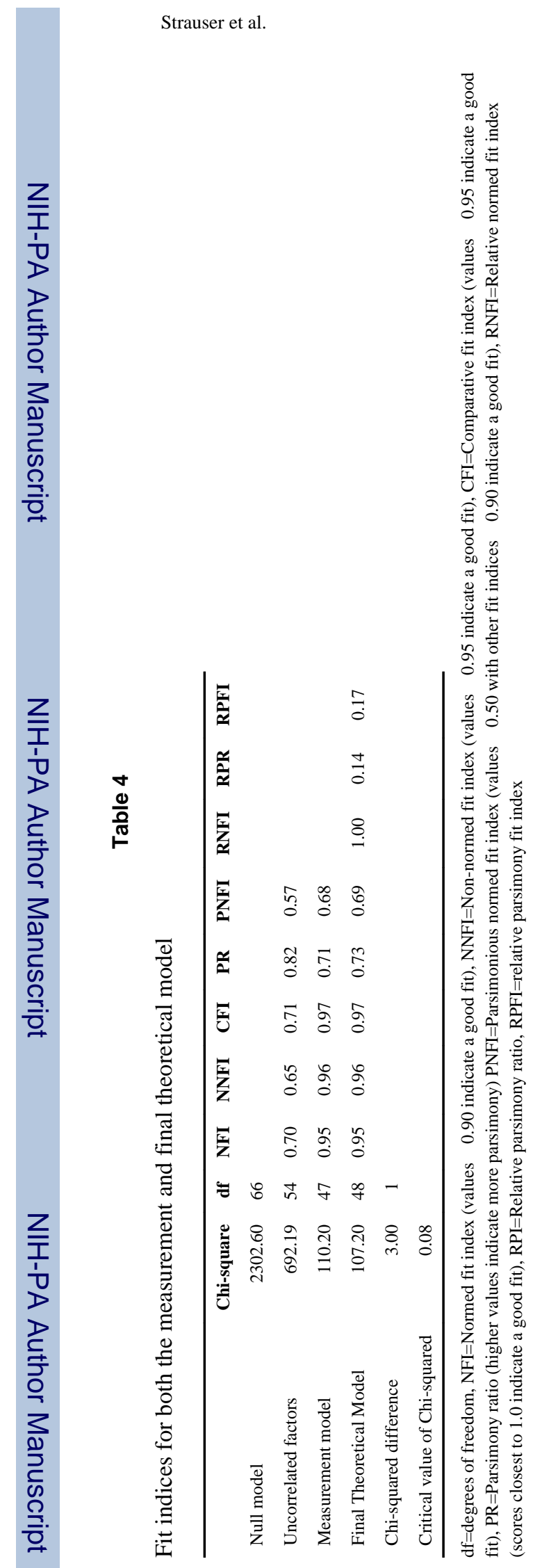

J Cancer Surviv. Author manuscript; available in PMC 2016 March 01. 
Table 5

Standardized path coefficients for the final model

\begin{tabular}{|c|c|c|c|c|c|}
\hline Dependent Variable & Independent variable & Standardized path coefficient & t-statistic & p-value & Variance explained \\
\hline \multirow[t]{3}{*}{ Career Thoughts } & & & & & 0.63 \\
\hline & Vocational Identity & -0.76 & 16.53 & $<0.001$ & \\
\hline & Emotional health & 0.07 & 1.74 & 0.08 & \\
\hline \multirow[t]{4}{*}{ Vocational Identity } & & & & & 0.35 \\
\hline & Emotional health & -0.43 & 7.62 & $<0.001$ & \\
\hline & Physical health & 0.13 & 2.67 & 0.01 & \\
\hline & Age group at diagnosis & 0.11 & 2.32 & 0.02 & \\
\hline \multirow[t]{3}{*}{ Emotional health } & & & & & 0.10 \\
\hline & Physical health & -0.32 & 5.74 & $<0.001$ & \\
\hline & Treatment intensity & -0.09 & 1.36 & 0.17 & \\
\hline
\end{tabular}

J Cancer Surviv. Author manuscript; available in PMC 2016 March 01. 